\title{
Corrigendum: Comparison of changes in the buccal keratinized mucosa between the minimally-invasive crestal incision and apically-positioned full-thickness flap methods for stage-two implant surgery
}

Keon-Il Yang ${ }^{1}$, Jun-Mo Yang ${ }^{2}$, Ki-Won Lee ${ }^{2}$, Won-Pyo Lee ${ }^{3}$, Byung-Ock Kim ${ }^{4}$, and Sang-Joun Yü*

${ }^{1}$ Clinical Professor, Department of Periodontology, Chosun University School of Dentistry, Gwangju, Republic of Korea ${ }^{2}$ Graduate Student, Department of Periodontology, Chosun University School of Dentistry, Gwangju, Republic of Korea ${ }^{3}$ Assistant Professor, Department of Periodontology, Chosun University School of Dentistry, Gwangju, Republic of Korea ${ }^{4}$ Professor, Department of Periodontology, Chosun University School of Dentistry, Gwangju, Republic of Korea

(c) This is an open-access article distributed under the terms of the Creative Commons Attribution Non-Commercial License (http://creativecommons.org/licenses/by-nc/4.0) which permits unrestricted noncommercial use, distribution, and reproduction in any medium, provided the original work is properly cited.

Correction to: Oral Biol Res 2020;44:45-50, https://doi.org/10.21851/obr.44.01.202003.45

In the originally published version of this article was error in the author's affiliation, which should be properly revised as follows:

\section{Before correction:}

Ki-Won Lee ${ }^{3}$

${ }^{3}$ Doctor of Dental Clinic, Samho Myeongin Clinic, Yeongam, Republic of Korea

After correction:

Ki-Won Lee ${ }^{2}$

${ }^{2}$ Graduate Student, Department of Periodontology, Chosun University School of Dentistry, Gwangju, Republic of Korea

\footnotetext{
${ }^{\star}$ Corresponding author: Sang-Joun Yu, Department of Periodontology, Chosun University School of Dentistry, 309 Pilmun-daero, Dong-gu, Gwangju 61452, Republic of Korea.

Tel: +82-62-220-3850, Fax: +82-62-224-4664, E-mail: sjyu78@chosun.ac.kr
}

Copyright $\odot$ 2021, Oral Biology Research Institute 